\section{Mission Accomplished}

Fernando Bacal

Editor-in-Chief, 2008-2009
At the end of this month of December, 2009, I shall have completed 4 years living the daily life of the Brazilian Archives of Cardiology: two of them as the Executive Director and two others, during the 2008-2009 period, as the journal's Editor-in-Chief. I leave with a feeling of having had my mission accomplished, having witnessed the great development and professional growth of the Archives.

The main accomplishments of our term were the implementation of the Spanish version of the journal, the close contact with the post-graduation programs, which established a link and a commitment with the publication of important scientific contributions from post-graduation programs and the internationalization of the journal - with meetings, symposia, exchange programs and joint editorials with the editors of the main journals in Portuguese and Spanish languages. Moreover, we also created tools to expedite the editorial process, such as the list of similar publications already published at the Archives, facilitating the work of reviewers, the certification given to reviewers that have issued technical reports, the automatic list of reviewers per area of review, facilitating the work of the Associated Editors, the Ahead of Print tool, making available in the Internet the articles that will be published shortly and the acquisition of funds from $\mathrm{CNPq}$ for the journal editing.

I have always highlighted the importance of creating a "virtuous cycle", in which we would receive better studies and as they were being published, they would generate more submissions, contributing to the impact factor of the journal. This phenomenon can already be detected, as we analyze the growing number of submissions, with more than 90 original studies submitted during this biannual period when compared to the prior one. We also demonstrated the growing number of original international articles, which showed that the journal has become quite attractive for foreigner authors as well. The impact factor of the journal by the ISI will be published up to June 2010, which will determine the B2 CAPES classification, therefore quite attractive for the Post-Graduation Programs, representing around $60 \%$ of all original articles published during the biannual period, which definitely represents a great advancement.

We also published a high number of Guidelines and among them the I Brazilian Guidelines on Cardiovascular Disease Prevention in Climacteric Women and the Influence of Hormonal Replacement Therapy (HRT), Guidelines on

Mailing address: Fernando Bacal •

Av. Divino Salvador, 395 apt. 201, 2o andar - Planalto Paulista - 04078-011

- São Paulo - SP

Email: fbacal@cardiol.br
Percutaneous Coronary Intervention and Adjunct Diagnostic Methods in Interventionist Cardiology (II Edition - 2008), Guidelines of the Brazilian Society of Cardiology on Professional and Institutional Quality, Training Center and Professional Certification and Certification in Hemodynamics and Interventionist Cardiology (II Edition - 2008), Brazilian Guidelines of Atrial Fibrillation, III Brazilian Guidelines on Chronic Heart Failure and I Brazilian Guidelines on Acute Heart Failure, in addition to others that have already been finished and are soon to be published.

Evidently, these results are the fruit of teamwork. I would like to thank the Associated Editors who have worked hard with me during these last two years (Roberto Rocha Giraldez, Pedro A. Lemos, Leonardo A. M. Zornoff, Lucia Campos Pellanda, Andre d'Avila, Estela Azeka, Luiz Felipe P. Moreira, Iran Castro and Carisi A. Polanczyk). I also thank the partnership, trust and support given by the Director of Communications, Renato A Kalil, the President of the Brazilian Society of Cardiology (SBC), Antonio Carlos P. Chagas and all the members of the Board of Directors during our two-year term.

I also would like to thank the reviewers who worked so hard and gave their invaluable time to contribute to the journal and the internal operational team of the Brazilian Archives of Cardiology, represented by the Editorial Supervisor, Deborah Moratori, who spared no effort, together with her entire team, to incessantly strive for what we had defined as the "journal of our dreams", a goal that has yet to be achieved, but which is completely achievable in a near future.

It is clear that we still have a long way to go, but we are undoubtedly on the right path. The challenges that will appear from now on are bigger ones, as the expectations will also increase. I wish Luis Felipe Moreira, who will take over as the first Professional Editor of the journal, with a four-year term, the greatest success in this journey and I am sure that the diagnoses for the constant improvement of the journal have already been made and will soon be implemented by him and his team.

I thank the congratulations and the vote of confidence that I have received throughout these years, as well as the criticism and complaints, which were essential for the attempt to do it right. I also would like to make a tribute to those who helped with the journal viability and the researchers and cardiologists who have read and published articles in the Brazilian Archives of Cardiology, the main motivation behind the fight for a strong journal, such as ours.

Thank you. 